\title{
Normal gastric emptying time of a carbohydrate-rich drink in elderly patients with acute hip fracture: a pilot study
}

\author{
Per M. Hellström ${ }^{1 *}$, Bodil Samuelsson ${ }^{2,3}$, Amer N. Al-Ani $^{4}$ and Margareta Hedström ${ }^{4}$
}

\begin{abstract}
Background: Guidelines for fasting in elderly patients with acute hip fracture are the same as for other trauma patients, and longer than for elective patients. The reason is assumed stress-induced delayed gastric emptying with possible risk of pulmonary aspiration. Prolonged fasting in elderly patients may have serious negative metabolic consequences. The aim of our study was to investigate whether the preoperative gastric emptying was delayed in elderly women scheduled for surgery due to acute hip fracture.
\end{abstract}

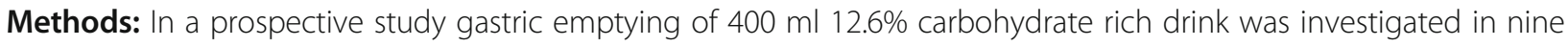
elderly women, age $77-97$, with acute hip fracture. The emptying time was assessed by the paracetamol absorption technique, and lag phase and gastric half-emptying time was compared with two gender-matched reference groups: ten elective hip replacement patients, age 45-71 and ten healthy volunteers, age 28-55.

Results: The mean gastric half-emptying time in the elderly study group was $53 \pm 5$ (39-82) minutes with an expected gastric emptying profile. The reference groups had a mean half-emptying time of $58 \pm 4$ (41-106) and $59 \pm 5$ (33-72) minutes, indicating normal gastric emptying time in elderly with hip fracture.

Conclusion: This pilot study in women with an acute hip fracture shows no evidence of delayed gastric emptying after an orally taken carbohydrate-rich beverage during the pre-operative fasting period. This implies no increased risk of pulmonary aspiration in these patients. Therefore, we advocate oral pre-operative management with carbohydraterich beverage in order to mitigate fasting-induced additive stress in the elderly with hip fracture.

Trial registration: ClinicalTrials.gov NCT02753010. Registered 17 April 2016, retrospectively.

Keywords: Aspiration, Carbohydrate loading, Metabolism, Nutrition, Surgery

\section{Background}

Over the last decade the guidelines for fasting in preparation for immediate surgery have changed. Clear fluids are now recommended within two hours before induction of anesthesia in patients without known risks of pulmonary aspiration [1]. The guidelines for patients considered to be at increased risk of delayed gastric emptying, including trauma patients are however unchanged [1]. In hip fracture patients, the injury by itself, including the acute mental stress, are factors that theoretically can influence and delay gastric emptying. But

\footnotetext{
* Correspondence: Per.Hellstrom@medsci.uu.se

'Department of Medical Sciences, Uppsala University, SE-75185 Uppsala, Sweden

Full list of author information is available at the end of the article
}

also other common factors in this patient group can influence the gastric emptying rate, as for example, old age [2], diabetes mellitus [3] renal insufficiency [4], and the use of opioid analgesics [5].

Apart from being elderly and possibly suffering from different comorbidities, patients admitted with a hip fracture often are in a poor nutritional condition [6-8]. In spite of this, these patients are commonly kept fasting in preparation for surgery and may later even be reprioritized for surgery leading to further prolonged fasting time. Hence, waiting times up to, and even beyond $24 \mathrm{~h}$ with continuous fasting is not uncommon [9]. During prolonged fasting, the patient suffers a risk of energy depletion, with consequent harmful effects on general health condition [10]. To avoid this, the patient should be 
operated as early as possible after admission with adequate energy substitution, primarily of proteins and carbohydrates. Oral intake of $200 \mathrm{kcal}$ carbohydrates triggers a release of insulin similar to that after a light meal [11], which should be positive from a nutritional perspective. As an alternative, if intravenous administration is chosen, an equal amount of carbohydrates (i.e. $1000 \mathrm{~mL} \mathrm{5 \%} \mathrm{glu-}$ cose solution) causes only a limited insulin response [12, 13], which also means that the anabolic effect of insulin is little. Preoperative carbohydrates provided in the form of a beverage have been shown to have several other benefits, such as reduced preoperative thirst, hunger and anxiety [14]. All these positive properties of preoperative carbohydrate feeding instead of fasting should be considered in the medical care of elderly patients with a hip fracture.

The primary aim of the study was to investigate if gastric emptying rate is delayed in elderly hip fracture patients using a $400 \mathrm{~mL}$ carbohydrate-rich beverage as nutritional supply. This was as compared to two gendermatched comparator groups, one old and one young. The secondary aim of the study was to study if the carbohydrate-rich beverage could be administered within two hours prior to surgery without risk of pulmonary aspiration.

\section{Methods}

This prospective study was approved by the regional ethics committee Karolinska Institutet (dnr 02-123), and complies with the principles laid down in the Declaration of Helsinki. The ClinicalTrials.gov identifier is NCT02753010. Informed consent was given after the patient had received written and oral information.

\section{Patient characteristics}

Ten patients, 77-97 years old (median 87), randomly recruited among those admitted with an acute hip fracture to Danderyd Hospital, Stockholm, Sweden, were recruited during a period of 12 months. Inclusion criteria were: female gender, age 75 years or above, and hip fracture within $24 \mathrm{~h}$ of admission. Exclusion criteria were: gastro-esophageal reflux disease, peptic ulcer disease, gastrointestinal motility disorder, pulmonary or cardiac disease, pharmacological treatment with motility-stimulating agents such as dopamine receptor blockers or macrolides, as well as previous long-term opioids or acid inhibitory agents, or cognitive impairment at the discretion of the investigator. Three patients did not have any previous disease or medication. Two suffered from diabetes mellitus, one substituted with insulin, the other under treatment with oral anti-diabetic drugs (glibenclamide). Two patients suffered from hypothyroidism, which was substituted with thyroxine.
One patient had a history of stroke but was freely ambulant.

The study was conducted in the morning hours during fasting before surgery. Of the included nine patients, two were given morphine intravenously in the morning immediately prior to intervention (i.e. intake of beverage). During the intervention, starting $180 \mathrm{~min}$ prior to surgery, the patients had infusions with $5 \%$ glucose, and for diabetics $10 \%$ glucose $100 \mathrm{~mL} / \mathrm{h}$ with insulin added to maintain blood sugar below $10 \mathrm{mmol} / \mathrm{L}$. All patients underwent surgery under spinal anaesthesia according to routines. No adverse events were observed peri-operatively. The results were compared with two reference groups of 20 gender-matched subjects. One group consisted of $10 \mathrm{fe}-$ male patients (age 45-71) on the waiting list for elective hip replacement surgery due to osteoarthritis [15]. The other group consisted of healthy female volunteers (age 28-55). All participants in the three groups were nonsmokers and had normal body mass index.

Two-hundred $\mathrm{mL}$ of an iso-osmolar carbohydrate-rich drink (50 kcal, $12.6 \%$ carbohydrates per $100 \mathrm{~mL}, \mathrm{pH} 5.0$, Nutricia Preop; Numico; Zoetermeer, The Netherlands), was first given. Then, $1.5 \mathrm{~g}$ of paracetamol dissolved in $100 \mathrm{~mL}$ water was taken and thereafter another $200 \mathrm{~mL}$ of the carbohydrate-rich drink resulting in a total volume of $500 \mathrm{~mL}$. This beverage has been approved by the Swedish Medicines Agency for use close to surgery.

In the two reference groups, the beverage was given to the patients in an upright sitting position. In the experimental group, due to the fracture-related pain, a halfsupine position was allowed. If needed, additional intravenous morphine was allowed according to usual routines. Vomiting and nausea were registered.

Gastric emptying rate was assessed by the paracetamol absorption technique: after oral ingestion, the absorption of paracetamol is used as an indirect measure of the rate of gastric emptying. Using blood samples, plasma was obtained for measurement of paracetamol concentration at $0,15,30,60,120$ and 180 min after the total intake of beverage and paracetamol solution.

The paracetamol absorption technique has been described and validated earlier, and shown to correlate well with other methods of measuring gastric emptying [16-18]. The method was adapted from that described by Näslund et al. [18], and the concentration of paracetamol (acetaminophen) was measured by HPLC (Sigma-Aldrich, St. Louis, MO; standard UC448) with a coefficient of variation of 5\%. A statistical limit for significance was set at $5 \%$.

\section{Data analysis}

Gastric emptying was compared between the groups using the lag phase, half-emptying time and complete emptying. The lag phase was defined as emptying of $2 \%$ 
of gastric contents, whereas gastric half-emptying time (T50) was defined as the period from the end of beverage intake with paracetamol until $50 \%$ of gastric emptying was achieved, and complete emptying as the time point when no more absorption of paracetamol occurred [17]. The gastric emptying profile was estimated after conversion of plasma paracetamol concentration values to cumulated values, i.e. total absorption of the drug. In this way we obtained a gastric emptying curve from $0 \%$ to $100 \%$ adapted to a third-order polynomial. The sample size $n=10$ was calculated based on a $\pm 20 \%$ minimum detectable effect and a statistical significance of $95 \%$. For statistical evaluation of differences between the groups, the Kruskal-Wallis test with Dunn's post hoc test was used. Results are given as medians with minimum and maximum values as well as means with the 95\% confidence interval within parenthesis.

\section{Results}

All 10 patients in the acute hip fracture group were fasted from midnight, implicating at least eight hours strict fasting before the oral carbohydrate-loading beverage was taken. Nine of the ten included patients were analyzed; one patient excluded due to incidental morphine treatment with concomitant nausea and vomiting.

The gastric emptying was comparable between the three groups with a typical curve shape showing an initial lag phase, followed by an emptying phase and finally tailing-off with complete emptying of the stomach at $180 \mathrm{~min}$. The lag phase before emptying took place was not delayed in any of the groups that underwent surgery and similar to the healthy controls (Table 1). After onset of the emptying process the gastric emptying rate was similar in all groups as verified by the half-emptying time (T50). In the acute hip fracture group, the gastric

Table 1 Gastric half-emptying time of $400 \mathrm{~mL}$ carbohydrate-rich drink in three groups of women

\begin{tabular}{llll}
\hline & $\begin{array}{l}\text { Acute hip } \\
\text { fracture patients } \\
(n=9)\end{array}$ & $\begin{array}{l}\text { Elective hip } \\
\text { surgery patients } \\
(n=10)\end{array}$ & $\begin{array}{l}\text { Healthy } \\
\text { volunteers } \\
(n=10)\end{array}$ \\
\hline $\begin{array}{l}\text { Age, years, median } \\
\text { (range) }\end{array}$ & $87(77-97)$ & $59(45-71)$ & $41(28-55)$ \\
$\begin{array}{l}\text { Lag phase, minutes, } \\
\text { median (min-max) }\end{array}$ & $1(0-7)$ & $3.5(0-11)$ & $1(0-4)$ \\
$\begin{array}{l}\text { Lag phase, minutes, } \\
\text { mean (95\% Cl) }\end{array}$ & $2.1(0.1-4.1)$ & $3.6(1.0-6.2)$ & $1.5(0.5-2.5)$ \\
$\begin{array}{l}\text { T50, minutes, median } \\
\text { (min-max) }\end{array}$ & $53(39-82)$ & $58(41-87)$ & $59.5(33-72)$ \\
$\begin{array}{l}\text { T50, minutes, mean } \\
(95 \% \text { Cl) }\end{array}$ & $57(45.5-68.5)$ & $59.6(50-69.2)$ & $58.6(50.2-67.0)$ \\
\hline
\end{tabular}

Gastric emptying assessed by the paracetamol absorption technique. Lag phase, emptying of $2 \%$ of gastric contents; T50, gastric half-emptying time, $50 \%$ emptying of contents. Carbohydrate beverage: $50 \mathrm{kcal}, 12.6 \%$ carbohydrates/100 mL, pH 5.0 (Nutricia Preop; Numico; Zoetermeer, The Netherlands). $\mathrm{Cl}$, confidence interval half-emptying time was $57 \pm 5$ (39-82) minutes. In the two reference groups the half-emptying times were $58 \pm 4$ (41-106) minutes in the group of females scheduled for hip replacement, and $58 \pm 5$ (33-72) minutes in the control group of healthy female volunteers (age 28-55) (Table 1, Fig. 1). The gastric emptying profile displayed the expected slightly sigmoidal curve representing a thirdorder polynomial function according to which calculations of lag phase and T50 were made (Fig. 2). None of the patients experienced any acid regurgitation or aspiration. No other adverse effects of the intake of the beverage was encountered.

\section{Discussion}

In this pilot study we have evaluated gastric emptying in a comparably old and fragile group of patients admitted to hospital with an acute hip fracture. The results were evaluated against two gender-matched control groups; one of similar age range, another at younger age. Our data show no differences between the groups, neither of gastric emptying rate as evaluated by gastric halfemptying time, nor by gastric emptying profile which showed an expected curve form. These findings support the hypothesis that gastric emptying is not deranged even in comparably old patients. Hence, there is no motivation for an overnight fast in order to diminish the risk of gastric aspiration during anesthesia and surgery. With the ambition to ensure safe surgical procedures, commonly used guidelines recommend a prolonged preoperative fasting of at least $6 \mathrm{~h}$ as delayed gastric emptying in the elderly is presumed. This is based on the assumption that not only pain and stress caused by the injury, but also to high age and comorbidity should slow gastric emptying [19].

In our study group, the patients were elderly women with more than half of them over 90 years of age, and even though, we found no signs of slow gastric emptying even at high age. In studies of healthy subjects, the association between high age and delayed gastric emptying is

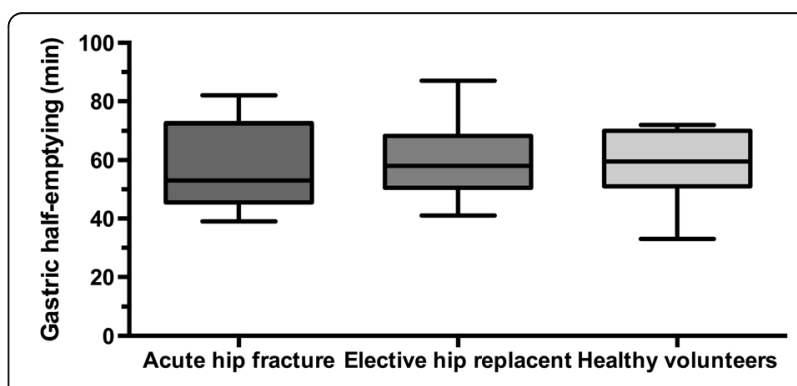

Fig. 1 Boxplots of gastric half-emptying time using the paracetamol absorption technique in three groups of women: Elderly women with acute hip fracture $(n=9)$, women with osteoarthritis scheduled for elective hip replacement $(n=10)$ and healthy female volunteers 


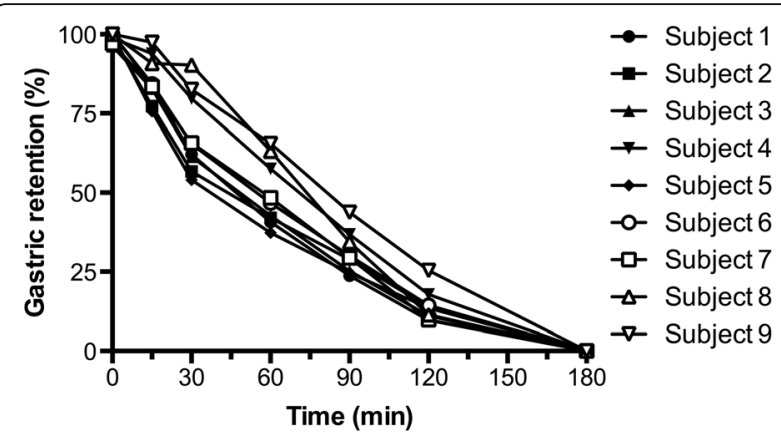

Fig. 2 Individual gastric emptying profiles of nine elderly women with acute hip fracture. In all patients the gastric emptying curve fulfilled requirements of a third-order polynomial sigmoid curve by which gastric lag phase, half-emptying times and complete emptying were calculated (see Table 1)

inconsistently reported [2, 15, 20-23]. In a previous study, we reported increased gastric emptying rate of solid food in women over 50 years of age as compared to young women. This seems to hold true even up to 80 years of age [16]. Opposed to this, studies in younger women below age 50 have reported slower gastric emptying rate with solids [16, 20, 23]. In our hands all three groups of women had similar gastric emptying rate suggesting a similar gastric emptying of a liquids, such as a carbohydrate beverage.

In this patient category of elderly women concomitant drug treatment with opioids as pain-killers may prolong gastric emptying rate, thereby putting the patient at risk of pulmonary aspiration $[5,20]$. In this study two of the three patients who received opioids pre-operatively displayed normal gastric emptying rates, whereas one patient suffered from nausea and vomiting and was excluded from the study. This patient also had considerable comorbidity with chronic renal failure and anemia, risk factors for delayed gastric emptying [4]. Diabetes mellitus has also been considered as a major cause of gastric emptying comprising 30-50\% of individuals with diabetes [24, 25]. However, this complication seems to be confined to the gastric emptying of solids and not liquid contents [26]. In line with this, among the patients in our study comorbidities such as hypothyroidism, diabetes, and even renal failure had no effect on the gastric emptying rate. In practical terms, our results indicate that there is a reason for concern when opioids are used preoperatively, but the risk of aspiration seems to be limited and nausea may caution against the risk of aspiration. It therefore seems that in the majority of acute hip fracture patients gastric emptying of liquids is not affected in the pre-operative phase. This opens the possibility of using a carbohydraterich beverage in order to delimit the stress-related metabolic derangement induced by prolonged fasting and should be considered for optimizing post-surgical recovery in the elderly.

Gastric emptying of a carbohydrate-rich beverage has previously been studied in hip fracture patients. A volume of $200 \mathrm{~mL}$ has been given close to induction of anesthesia and the emptying rate as well as risk of pulmonary aspiration evaluated. Even though the study design was different from ours, findings were similar and none of the patients showed delayed gastric emptying and no pulmonary aspiration occurred [27]. Moreover, to improve the quality of care for hip fracture patients, some surgical centers have now decided to deviate from strict fasting routines, also in elderly patients. Hence, a recently published study employing a multimodal optimization package for hip fracture patients claim that all patients were allowed clear fluids up to $3 \mathrm{~h}$ before surgery [28].

This limited pilot study cannot exclude the risk of incidental drawbacks such as pulmonary aspiration and vomiting in large series of patients in routine medical care. However, our study as well as previous reports [27] indicate that this is not the case. Albeit, special care has to be taken to patients with agonizing nausea, especially after opioid use, who may be at risk.

We did not include a specific pain scoring to relate to the gastric emptying as this was not crucial for testing our hypothesis. Individual variations with regard to pain in this patient population have been reported in the literature, and the pain pattern reported in the current study was considered to be representative for a normal hip fracture population. It should be noted that although two of the patients in our study received opioids that usually are considered to slow gastric emptying, we could not find this to be the case in these two individuals.

\section{Conclusions}

Taken together, this pilot study of elderly women with an acute hip fracture showed no evidence of prolonged gastric emptying time or incidents of aspiration. This means that a carbohydrate-rich beverage could be given close to surgery in order to prevent a prolonged metabolically deleterious fasting period which could delay the patients' recovery.

\section{Abbreviations}

ALF: Avtal om läkarutbildning och forskning (i.e. agreement on medical doctors' training and research in Sweden); Dnr: Diary number; HPLC: High performance liquid chromatography; MO: Missouri; T50: Gastric half-emptying time

\section{Acknowledgements}

Financial support was provided through the Regional Agreement on Medical Training and Clinical Research (ALF) between Stockholm County Council and Karolinska Institutet, Uppsala University, Swedish Orthopedic Association, King Gustaf the V and Queen Victoria's Freemasons Foundation, The National Board on Health and Welfare, Sweden, and Sophiahemmet Foundation. 


\section{Availability of data and materials}

Primary data and materials for the study are available through prof Per M. Hellström, Uppsala University, where primary data also are filed.

\section{Authors' contributions}

BS collected data, participated in design, analyses, interpretation of data and drafted the manuscript. PH carried out the design, performed the statistical calculations, participated in analyses and interpretation of data and critically reviewed the manuscript. AAA participated in analyses and interpretation of data. $\mathrm{MH}$ participated in the study design, analyses and interpretation of data, and drafted the manuscript. All authors read and approved the final manuscript.

\section{Competing interests}

The authors declare that they have no competing interests.

\section{Ethics approval and consent to participate}

The study was approved by the regional ethics committee at Karolinska Institutet (dnr 02-123), and complies with the principles laid down in the Declaration of Helsinki. The ClinicalTrials.gov identifier is NCT02753010. Informed consent to participate in the study was given after the patients had received written and oral information.

\section{Author details}

${ }^{1}$ Department of Medical Sciences, Uppsala University, SE-75185 Uppsala, Sweden. ${ }^{2}$ Department of Clinical Sciences, Division of Orthopedics, Karolinska Institutet, Danderyd Hospital, Stockholm, Sweden. ${ }^{3}$ Sophiahemmet University College, Stockholm, Sweden. ${ }^{4}$ Department of Clinical Science and Technology (Clintec), Division of Orthopedics, Karolinska Institutet, Karolinska University Hospital, Huddinge, Sweden.

Received: 1 July 2016 Accepted: 30 December 2016

Published online: 15 February 2017

\section{References}

1. Smith I, Kranke P, Murat I, et al. Perioperative fasting in adults and children: guidelines from the European Society of Anaesthesiology. Eur J Anaesthesiol. 2011;28:556-69.

2. Moore JG, Tweedy C, Christian PE, et al. Effect of age on gastric emptying of liquid-solid meals in man. Dig Dis Sci. 1983;28:340-4

3. Horowitz M, O'Donovan $\mathrm{D}$, Jones $\mathrm{KL}$, et al. Gastric emptying in diabetes: an overview. Diabet Med. 1996:13:S16-22.

4. Strid H, Simrén M, Stotzer P-O, et al. Delay in gastric emptying in patients with chronic renal failure. Scand J Gastroenterol. 2004:39:516-20.

5. Milligan KR, Howe JP, McClean E, et al. Postoperative gastric emptying in outpatient anesthesia: the effect of opioid supplementation. J Clin Anesth 1988;1:9-11.

6. Olofsson B, Stenvall M, Lundström $M$, et al. Malnutrition in hip fracture patients: an intervention study. J Clin Nurs. 2007;16:2027-38.

7. Orsitto G, Fulvio F, Tira D, et al. Nutritional status in hospitalized elderly patients with mild cognitive impairment. Clin Nutr. 2009;28:100-2.

8. Ponzer S, Tidermark J, Brismar K, et al. Nutritional status, insulin-like growth factor-1 and quality of life in elderly women with hip fractures. Clin Nutr. 1999;18:241-6.

9. Simunovic N, Devereaux PJ, Sprague $S$, et al. Effect of early surgery after hip fracture on mortality and complications: systematic review and metaanalysis. CMAJ. 2010;182:1609-16.

10. Eneroth M, Olsson UB, Thorngren KG. Insufficient fluid and energi intake in hospitalised patients with hip fracture. A prospective randomised study of 80 patients. Clin Nutr. 2005;24:297-303.

11. Nygren J, Thorell A, Jacobsson $\mathrm{H}$, et al. Preoperative gastric emptying. Effects of anxiety and oral carbohydrate administration. Ann Surg. 1995;222:728-34.

12. Nygren J, Soop M, Thorell A, et al. Preoperative oral carbohydrate administration reduces postoperative insulin resistance. Clin Nutr. 1998;17:65-71.

13. Soop M, Nygren J, Myrenfors $P$, et al. Preoperative oral carbohydrate treatment attenuates immediate postoperative insulin resistance. Am J Physiol Endocrinol Metab. 2001;280:E576-83.
14. Hausel J, Nygren J, Lagerkranser M, et al. A carbohydrate-rich drink reduces preoperative discomfort in elective surgery patients. Anesth Analg. 2001;93:1344-50.

15. Aronsson A, Al-Ani NA, Brismar K, et al. A carbohydrate-rich drink shortly before surgery affected IGF-1 bioavailability after a total hip replacement. A double blind placebo controlled study on 29 patients. Aging Clin Exp Res. 2009;21:97-101.

16. Grybäck P, Hermansson G, Lyrenäs E, et al. Nationwide standardisation and evaluation of scintigraphic gastric emptying: reference values and comparisons between subgroups in a multicentre trial. Eur J Nucl Med. 2000;27:647-55

17. Maddern G, Miners J, Collin PJ, et al. Liquid gastric emptying assessed by direct and indirect techniques: radionuclide labelled liquid emptying compared with a simple paracetamol marker method. Aust N Z J Surg. 1985;55:203-6.

18. Näslund E, Bogefors J, Grybäck H, et al. Gastric emptying: comparison of scintigraphic, polyethylene glycol dilution, and paracetamol tracer assessment techniques. Scand J Gastroenterol. 2000;35:375-9.

19. Soreide E, Soop M, Nygren J, et al. Pre-operative fasting guidelines: an update. Acta Anaesthesiol Scand. 2005:49:1041-7.

20. Petring OU, Blake DW. Gastric emptying in adults: an overview related to anaesthesia. Anaesth Intensive Care. 1993:21:774-81.

21. Tougas G, Chen Y, Coates G, et al. Assessment of gastric emptying using a low fat meal: establishment of international control values. Am J Gastroenterol. 2000;95:1456-62

22. Jonderko K, Jonderko G, Marcisz C, et al. Gastric emptying in hyperthyroidism. Am J Gastroenterol. 1997:92:835-8.

23. Lobo DN, Hendry PO, Rodrigues G, et al. Gastric emptying of three liquid oral preoperative metabolic preconditioning regimens measured by magnetic resonance imaging in healthy adult volunteers: a randomised double-blind, crossover study. Clin Nutr. 2009;28:636-41.

24. Koch KL, Calles-Escandón J. Diabetic gastroparesis. Gastroenterol Clin North Am. 2015:44:39-57.

25. Jones KL, Russo A, Stevens JE, et al. Predictors of delayed gastric emptying in diabetes. Diabetes Care. 2001:24:1264-9.

26. Wright RA, Clemente R, Wathen R. Diabetic gastroparesis: an abnormality of gastric emptying of solids. Am J Med Sci. 1985;289:240-2.

27. Protic A, Turina D, Matanic D, et al. Effect of preoperative feeding on gastric emptying following spinal anesthesia: a randomized controlled trial. Wien Klin Wochenschr. 2010;122:50-3.

28. Macfie D, Arsalani Zadeh R, Anderws M, et al. Perioperative multimodal optimisation in patients undergoing surgery for fractured neck of femur. Surgeon. 2012;10:90-4

\section{Submit your next manuscript to BioMed Central and we will help you at every step:}

- We accept pre-submission inquiries

- Our selector tool helps you to find the most relevant journal

- We provide round the clock customer support

- Convenient online submission

- Thorough peer review

- Inclusion in PubMed and all major indexing services

- Maximum visibility for your research

Submit your manuscript at www.biomedcentral.com/submit
) Biomed Central 